\title{
Relationship of Malocclusion with Self-Esteem \& Quality of Life of Adult Saudi Female Orthodontic Patients
}

\author{
Kavitha Odathurai Marusamy ${ }^{1}$, Ahmed Marghalani² ${ }^{2}$ Lujain Khaled Aljuhani ${ }^{3}$, \\ Shahd Nabil Alhelali ${ }^{4}$, Saravanan Ramasamy ${ }^{5}$, Ullal Anand Nayak ${ }^{6}$ \\ 1,2,3,4,6 Department of Preventive Dental Sciences, Ibn Sina National College for Medical Sciences, Al Mahjar, \\ Jeddah, Kingdom of Saudi Arabia, ${ }^{5}$ Department of Oral \& Maxillofacial Rehabilitation, Ibnsina National \\ College for Medical Sciences, Al Mahjar, Jeddah, Kingdom of Saudi Arabia.
}

ABSTRACT

\section{BACKGROUND}

Self-satisfaction can be influenced by malocclusion resulting in impairment of psychology, associated with low self-esteem (SE) and quality of life issues (QOL). Certain malocclusions and orthodontic treatment needs are related to QOL and they can affect the psychological development and social skills of adolescents and young adults, who are the most common orthodontic patients. This study was done to assess the self-esteem and Orthognathic Quality of Life (OQL) among female participants with different types of malocclusion in private orthodontic clinics in Jeddah.

\section{METHODS}

This questionnaire-based study evaluated the effect of orthodontic malocclusion on SE and QOL in female orthodontic patients with Class I, Class II, Class III malocclusion, crowded anterior teeth, proclined anterior teeth, open bite, and deep bite patients. Patients were evaluated before starting orthodontic treatment with Rosenberg's SelfEsteem Scale and the Orthognathic Quality of Life Questionnaire (OQLQ) to find any correlation with malocclusion severity.

\section{RESULTS}

The results indicated that females who had Class II proclination and Class II deep bite type of malocclusion had significantly higher negative SE compared to other types. In the oral function component of the OQLQ, Class II malocclusion had statistically significant higher OQLQ scores than Class I Open bite (mean difference $=6.11, \mathrm{P}=$ 0.004 ) and Class II Deep bite (mean difference $=4.88, \mathrm{P}=0.015$ ).

\section{CONCLUSIONS}

The results suggest that female orthodontic patients with severe Class II and / or severely protrusive lip profile, deep bite may have lower SE and QOL than those with crowding, open bite, and Class III malocclusion.

\section{KEY WORDS}

Self-esteem, Orthodontic Malocclusion, Female Adult Orthodontic Patients, Quality of Life
Corresponding Author:

Dr. Kavitha Oadthurai Marusamy, Assistant Professor, Orthodontics Division, Department of Preventive Dental Sciences, Ibnsina National College for Medical Sciences, Al Mahjar, Jeddah,

Kingdom of Saudi Arabia 21418.

E-mail:dr.omkavitha@gmail.com

\section{DOI: $10.14260 /$ jemds/2021/465}

How to Cite This Article:

Marusamy KO, Marghalani A, Aljuhani LK, et al. Relationship of malocclusion with selfesteem \& quality of life of adult Saudi female orthodontic patients. J Evolution Med Dent Sci 2021;10(30):2276-2280, DOI: $10.14260 /$ jemds/2021/465

Submission 20-02-2021, Peer Review 18-05-2021, Acceptance 25-05-2021, Published 26-07-2021.

Copyright (C) 2021 Kavitha Odathurai Marusamy et al. This is an open access article distributed under Creative Commons Attribution License [Attribution 4.0 International (CC BY 4.0)] 


\section{BACKGROUND}

Self-esteem is a person's overall sense of personal worth or value; he / she is self-judging. Self-esteem interferes with every aspect of a person's physical \& emotional health, and how they interact with society. ${ }^{1}$

High self-esteem causes self-respect, this individual will make a concentrated effort in the face of difficulties; their perseverance increases the probability of obtaining more success than failure. ${ }^{2}$ In contrast, low self-esteem causes the individual to fall behind the difficulties of life or to try, but without giving the best of himself. Negative self-esteem is related to negative affections such as pain, anguish, doubt, sadness, emptiness, guilt, and shame.

Adults now make up a good proportion of patients seeking orthodontic treatment, apart from multidisciplinary treatment, aesthetics are becoming important in adult patient's lives. For the majority of people, facial attractiveness immensely correlated with self-esteem linked with their social and professional relationships. ${ }^{3}$

Aesthetic appearance influences the improvement of self concept and self-esteem. Self-esteem could also be affected by the rejection of the body image perceived by itself. Smiling is fundamental for the expression of aesthetics in the face, and therefore the teeth contribute to this expression. Dental appearance can influence the psychosocial state of the individual and also the kindness, social class, and acceptance perceived by the rest. Nevertheless, people trust a person who smiles more than a person who does not.2,4

Dental aesthetics has a greater contribution to psychosocial well-being.5,6 Further patients with severe malocclusion involving the anterior teeth experience both emotional and psychosocial negative effects on their lives. It is often stressed that the patient's perception of the malocclusion is often different from that of the orthodontist.

Studies have found that females with severe malocclusion have negative effects on oral health-related quality of life (OHRQOL), predominantly psychosocial wellbeing.7,8,9 Patients' OHRQOL has improved after they completed orthodontic treatment than it was before or during treatment. ${ }^{10}$ In one particular study, orthodontic treatment completed students had higher self-esteem than untreated ones. Also, students who demonstrated greater negativity about their dental aesthetics had a greater self-perceived need for treatment. ${ }^{11}$

Low self-esteem adolescents had dissatisfaction with dental appearance, avoided smiling, and believed that having straight teeth necessitates success in life, in contrast, adolescents having a high level of positive feeling towards the orofacial region are more strongly related to selfperceiveness. ${ }^{12,13}$ The prime motivating factor for the decision to seek treatment in adult patients is to improve in dental aesthetics. ${ }^{14}$ These studies indicate that dental aesthetics in comparison to oral, physical, and functional statuses of the OHRQOL, has a greater impact on the psychological status of adult patients.

Thus, this study intended to assess the relationships between variables of malocclusion severity and psychosocial well-being in adult Saudi female patients using a self-esteem questionnaire before the start of orthodontic treatment.

\section{METHODS}

This descriptive, analytical cross-sectional study evaluates whether there is any difference in self-esteem (SE) and quality of life (QOL) using Rosenberg's self-esteem scale (RSES) (RSE) ${ }^{15}$ and the Orthognathic quality of life questionnaire (OQLQ) ${ }^{16}$ in different types of malocclusion which includes class I crowding, deep bite, open bite, class II malocclusion with anterior proclination and class III malocclusion. The study group included 435 female patients with a mean age of (22 \pm 3.8) undergoing orthodontic treatment at various orthodontic clinics in Jeddah, Saudi Arabia. Ethical committee clearance of Ibn Sina National College for medical sciences was obtained (approval no 017DP29112018). Each patient signed a consent form and agreed to volunteer participation. The study duration extended for a period of 10 months from Jan 2019.

Study group patients were chosen with the following criteria -

1. Healthy female patients between 18 and 30 years of age.

2. No craniofacial anomalies\& syndromes

3. Normal temporomandibular joint

4. No noticeable facial asymmetry;

5. No missing or impacted teeth except third molars;

6. No previous orthodontic treatment experience;

7. No active caries or periodontal disease.

The sample size was calculated using the Sample Size Determination Program Ver. 2.0.1 and matching the previous study. ${ }^{13}$ The participants who have consented to be a part of the study completed the RSE and OQLQ questionnaires before starting the orthodontic treatment. The RSE consisted of a positive or a negative response on a four - point Likert scale ranging from 'strongly agree' to 'strongly disagree'.17 Out of 10 questions 5 were positive, and 5 were negative. For each negative statement, the answer was counted and added to the total score. The RSE was between 10 and 40, and a higher RSE score indicated greater SE. The OQLQ mainly assessed QOL in dentofacial deformity patients ${ }^{16}$ by measuring four principal components (facial aesthetics, function, self-awareness of facial deformity, and social aspects) on a four-point scale. OQLQ dimensions were scored such that lower scores indicated better QOL, and the scores ranged between 0 and 88 .

\section{Statistical Analysis}

Frequencies and percentages were used for descriptive statistics for presenting categorical variables. The normality assumption (Shapiro-Wilk test, $\mathrm{P}>0.05$ ) showed that data was following a normal distribution, and hence mean and the standard deviation was used for continuous variables. Analysis of Variance (ANOVA) was used to compare the differences in mean scores of OQLQ - 22 and self-esteem between different age groups. A P - value less than 0.05 is considered statistically significant.

\section{RESULTS}

This study was done to assess the self-esteem and Orthognathic Quality of Life among female participants with different types of malocclusion. Self-esteem was measured 
using RSE. The RSE scale was divided into two parts: Positive Self-esteem (PSE) with items 1, 3, 4, 7, 10 and Negative Selfesteem (NSE) with items 2, 5, 6, 8, 9. In PSE, strongly disagree $(S D)=1$, Disagree $(D)=2$, Agree $(A)=3$, and Strongly Agree $(S A)=4$, whereas in NSE the scoring was made in the opposite direction $[S A=1, A=2, D=3, S D=4]$. The recorded scores of self-esteem items for our study population are given in Table 1.

\begin{tabular}{|c|c|c|c|c|c|}
\hline & & 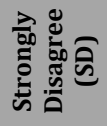 & 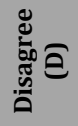 & 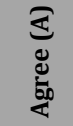 & 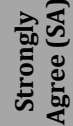 \\
\hline $\begin{array}{l}\text { 1. On the whole, I am satisfied with } \\
\text { myself. }\end{array}$ & $\begin{array}{l}\mathrm{N} \\
\%\end{array}$ & $\begin{array}{c}63 \\
(19.0)\end{array}$ & $\begin{array}{c}4 \\
(1.2)\end{array}$ & $\begin{array}{c}56 \\
(16.9)\end{array}$ & $\begin{array}{c}209 \\
(63.0)\end{array}$ \\
\hline 2. At times, I think I am no good at all. & $\begin{array}{l}\mathrm{N} \\
\%\end{array}$ & $\begin{array}{c}182 \\
(54.8)\end{array}$ & $\begin{array}{c}105 \\
(31.6)\end{array}$ & $\begin{array}{c}2 \\
(0.6)\end{array}$ & $\begin{array}{c}43 \\
(13)\end{array}$ \\
\hline $\begin{array}{l}\text { 3. I feel that I have a number of good } \\
\text { qualities. }\end{array}$ & $\begin{array}{l}\mathrm{N} \\
\%\end{array}$ & $\begin{array}{c}63 \\
(19.0)\end{array}$ & $\begin{array}{c}5 \\
(1.5)\end{array}$ & $\begin{array}{c}73 \\
(22.0)\end{array}$ & $\begin{array}{c}191 \\
(57.5)\end{array}$ \\
\hline $\begin{array}{l}\text { 4. I am able to do things as well as most } \\
\text { other people. }\end{array}$ & $\begin{array}{l}\mathrm{N} \\
\%\end{array}$ & $\begin{array}{c}60 \\
(18.1)\end{array}$ & $\begin{array}{c}2 \\
(0.6)\end{array}$ & $\begin{array}{c}80 \\
(24.1)\end{array}$ & $\begin{array}{c}190 \\
(57.2)\end{array}$ \\
\hline 5. I feel I do not have to be proud of. & $\begin{array}{l}\mathrm{N} \\
\%\end{array}$ & $\begin{array}{c}165 \\
(49.7)\end{array}$ & $\begin{array}{c}138 \\
(41.6)\end{array}$ & $\begin{array}{c}3 \\
(0.9)\end{array}$ & $\begin{array}{c}26 \\
(7.8)\end{array}$ \\
\hline 6. I certainly feel useless at times. & $\begin{array}{l}\mathrm{N} \\
\%\end{array}$ & $\begin{array}{c}180 \\
(54.2)\end{array}$ & $\begin{array}{c}120 \\
(36.1)\end{array}$ & $\begin{array}{c}3 \\
(0.9)\end{array}$ & $\begin{array}{c}29 \\
(8.7)\end{array}$ \\
\hline $\begin{array}{l}\text { 7. I feel that I am a person of worth, at } \\
\text { least on as equal plane with others. }\end{array}$ & $\begin{array}{l}\mathrm{N} \\
\%\end{array}$ & $\begin{array}{c}44 \\
(13.3)\end{array}$ & $\begin{array}{c}6 \\
(1.8)\end{array}$ & $\begin{array}{c}80 \\
(24.1)\end{array}$ & $\begin{array}{c}202 \\
(60.8)\end{array}$ \\
\hline $\begin{array}{l}\text { 8. I wish I could have more respect for } \\
\text { myself. }\end{array}$ & $\begin{array}{l}\mathrm{N} \\
\%\end{array}$ & $\begin{array}{c}195 \\
(58.7)\end{array}$ & $\begin{array}{c}84 \\
(25.3)\end{array}$ & $\begin{array}{c}1 \\
(0.3)\end{array}$ & $\begin{array}{c}52 \\
(15.7)\end{array}$ \\
\hline $\begin{array}{l}\text { 9. All in all, I am inclined to feel that I } \\
\text { am a failure. }\end{array}$ & $\begin{array}{l}\mathrm{n} \\
\%\end{array}$ & $\begin{array}{c}192 \\
(57.8)\end{array}$ & $\begin{array}{l}113 \\
(34)\end{array}$ & $\begin{array}{c}3 \\
(0.9)\end{array}$ & $\begin{array}{c}24 \\
(7.2)\end{array}$ \\
\hline $\begin{array}{l}\text { 10. I take a positive attitude towards } \\
\text { myself. }\end{array}$ & $\begin{array}{l}\mathrm{N} \\
\% \\
\end{array}$ & $\begin{array}{c}45 \\
(13.6) \\
\end{array}$ & $\begin{array}{c}1 \\
(0.3)\end{array}$ & $\begin{array}{c}81 \\
(24.4) \\
\end{array}$ & $\begin{array}{c}205 \\
(61.7) \\
\end{array}$ \\
\hline \multicolumn{6}{|c|}{ Table 1. Scores of Self-Esteem Scale } \\
\hline \multicolumn{6}{|c|}{\begin{tabular}{|l} 
Positive self-esteem (PSE): Items $1,3,4,7,10[\mathrm{SA}=4 . \mathrm{A}=3 . \mathrm{D}=2 . \mathrm{SD}=1]$ \\
Negative self-esteem (NSE): Items $2,5,6,8,9[\mathrm{SA}=1 . \mathrm{A}=2 . \mathrm{D}=3 . \mathrm{SD}=4]$
\end{tabular}} \\
\hline
\end{tabular}

The RSE was between 10 and 40, and a higher RSE score indicated greater Self-esteem (SE). The mean self-esteem in our study was found to be $25.3 \pm 3.33$. The mean PSE and NSE scores were found to be $16.29 \pm 2.93$ and $8.33 \pm 2.44$ respectively [Table 2]. When we compared the SE score between different types of malocclusion, it was found that there was no statistical significance seen in total SE and PSE scores, but NSE scores showed significant differences (< 0.001 ) [Table 2, Figure 1]. The mean NSE scores were higher in Class II Proclination $(9.20 \pm 2.69)$ and class II deep bite $(8.82$ \pm 2.40 ). The post - hoc analysis with Bonferroni corrections showed that females who had Class II Proclination and class II deep bite type of malocclusion had significantly higher NSE scores when compared with Class I crowding $(\mathrm{P}=<0.001$ and $\mathrm{P}=0.001)$. This means that females who had Class II proclination and class II deep bite type of malocclusion had significantly higher negative SE compared to other types.

\begin{tabular}{|c|c|c|c|c|c|c|c|c|c|}
\hline & & & Malo & occlusi & on & & & & \\
\hline & & $\begin{array}{l}\text { Class I } \\
\text { Crowding }\end{array}$ & $\begin{array}{l}\text { Class I } \\
\text { Open } \\
\text { Bite }\end{array}$ & $\begin{array}{l}\text { Class } \\
\text { II } \\
\text { Deep } \\
\text { Bite }\end{array}$ & $\begin{array}{l}\text { Class II } \\
\text { Pro- } \\
\text { clination }\end{array}$ & $\begin{array}{l}\text { Class } \\
\text { III }\end{array}$ & Total & $\mathbf{F}$ & $\begin{array}{c}P \\
\text { Value }\end{array}$ \\
\hline PSE & $\begin{array}{c}\text { Mean } \\
\text { SD }\end{array}$ & $\begin{array}{c}16.84 \\
3.62\end{array}$ & $\begin{array}{c}16.36 \\
2.68\end{array}$ & $\begin{array}{c}15.94 \\
2.58\end{array}$ & $\begin{array}{c}16.41 \\
2.63\end{array}$ & $\begin{array}{c}16.09 \\
3.03\end{array}$ & $\begin{array}{c}16.29 \\
2.93\end{array}$ & 1.055 & 0.379 \\
\hline NSE & Mean & 7.29 & 8.10 & 8.82 & 9.20 & 8.38 & 8.33 & 5.915 & $<0.001$ \\
\hline Total & $\begin{array}{c}\text { SD } \\
\text { Mean } \\
\text { SD } \\
\end{array}$ & $\begin{array}{c}1.98 \\
24.13 \\
3.66 \\
\end{array}$ & $\begin{array}{c}2.39 \\
24.46 \\
3.33 \\
\end{array}$ & $\begin{array}{c}2.40 \\
24.76 \\
3.25 \\
\end{array}$ & $\begin{array}{c}2.69 \\
25.61 \\
2.89 \\
\end{array}$ & $\begin{array}{c}2.45 \\
24.47 \\
3.29\end{array}$ & $\begin{array}{c}2.44 \\
24.62 \\
3.33 \\
\end{array}$ & 1.399 & 0.234 \\
\hline & & $\begin{array}{r}\text { e 2. Comp } \\
\text { bet }\end{array}$ & $\begin{array}{l}\text { arison } 0 \\
\text { tween D }\end{array}$ & $\begin{array}{l}\text { of Two } \\
\text { ifferen }\end{array}$ & $\begin{array}{l}\text { Types of } \\
\text { t Maloccl }\end{array}$ & $\begin{array}{l}\text { Self-Es } \\
\text { usions }\end{array}$ & steem S & Score & \\
\hline
\end{tabular}

\section{Figure 1: Negative self-esteem scores in different types of malocclusion}

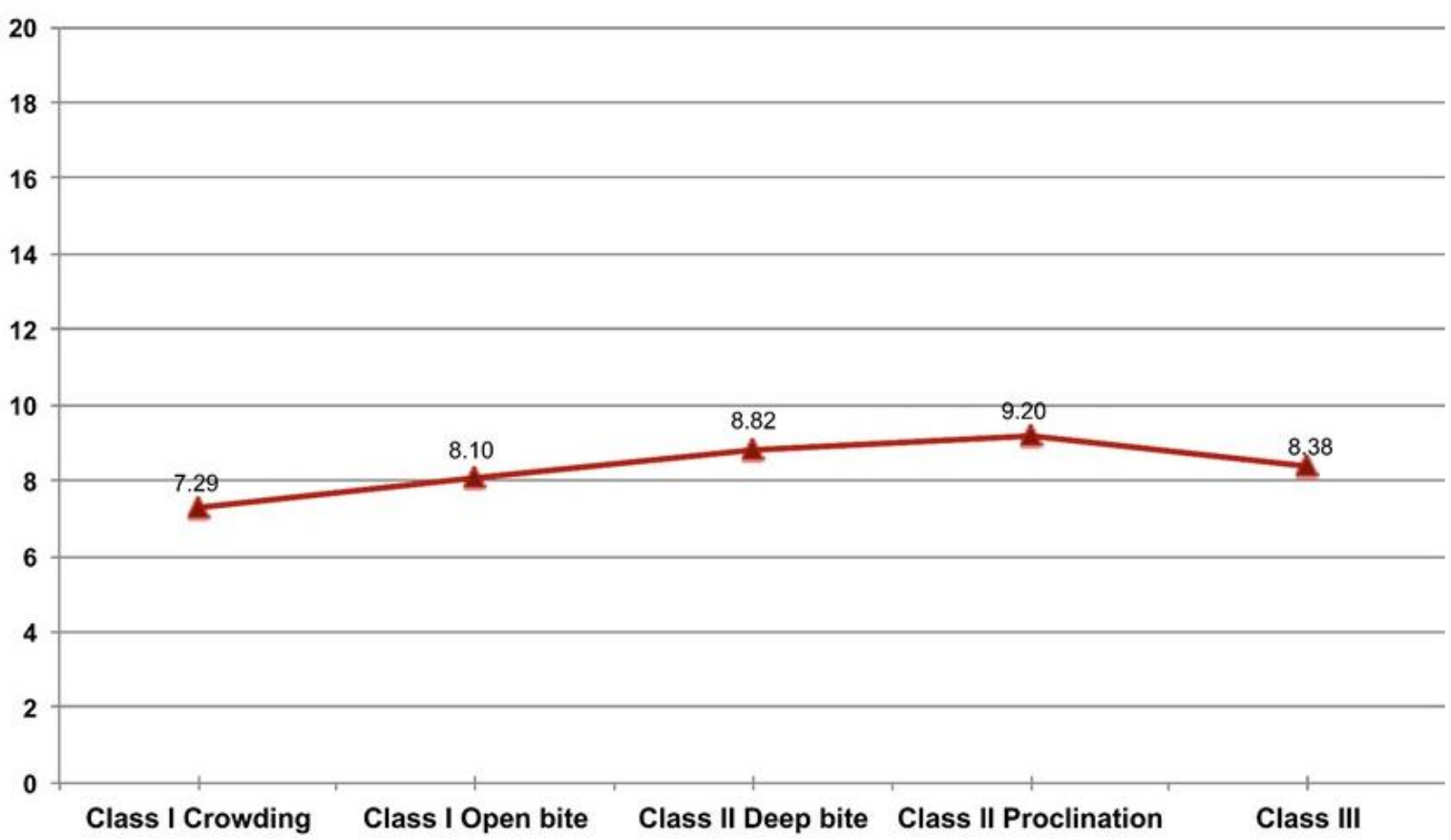




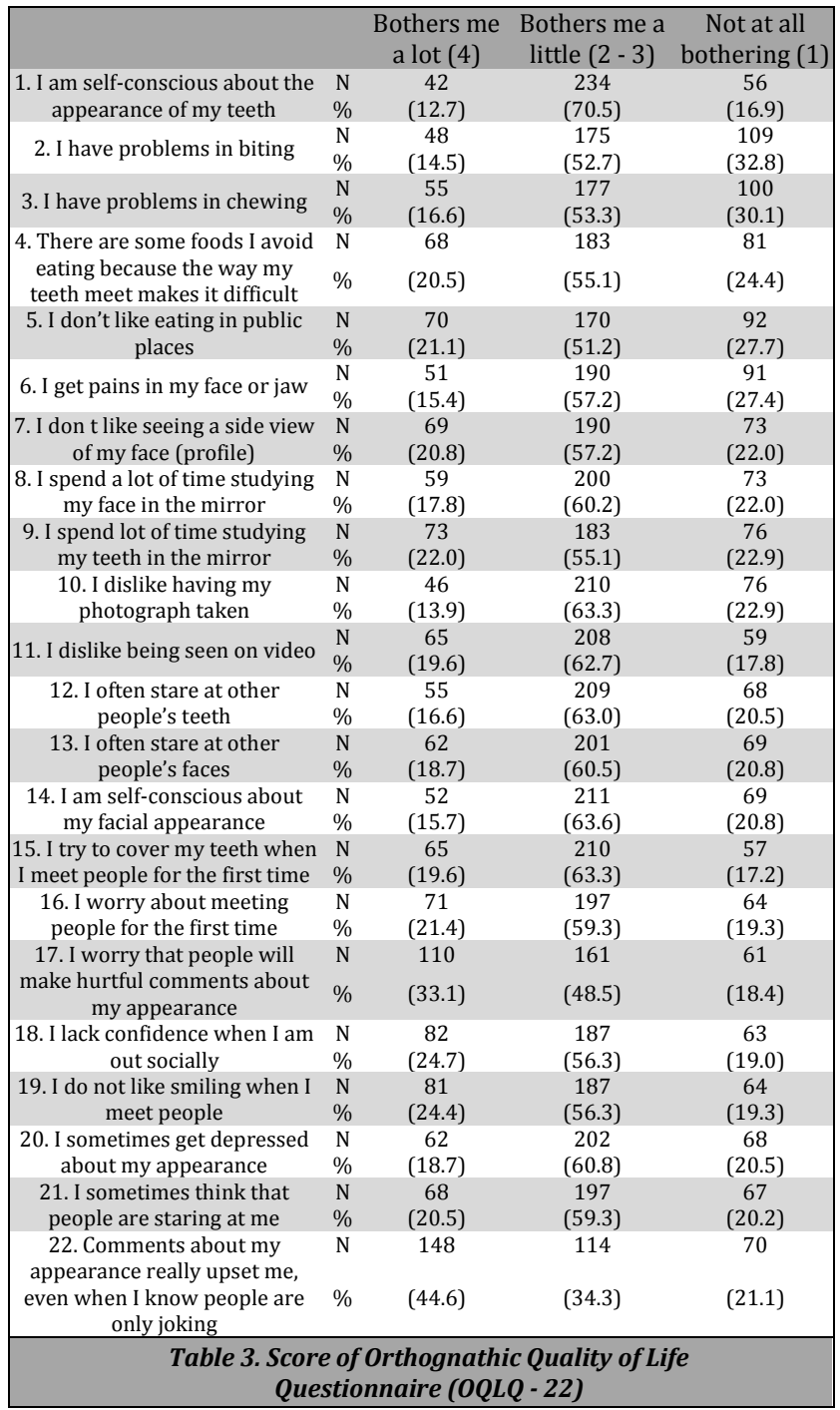

The Orthognathic Quality of Life Questionnaire (OQLQ) consisted of 22 questions measures positive to negative [Table 3]. The lower QOLQ scores indicate a better quality of life with a maximum score of 88 . The mean total score in our study was found to be $51.78 \pm 10.17$. The mean scores of each four components of OQLQ are given in Table 4.

\begin{tabular}{|c|c|c|c|c|c|c|c|c|}
\hline & & & Mal & occlusi & & & & \\
\hline & & 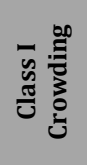 & 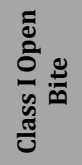 & 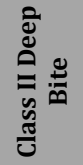 & = & 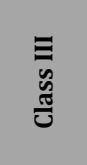 & I & $\begin{array}{l}\stackrel{0}{\Xi} \\
\frac{\pi}{2} \\
\vdots\end{array}$ \\
\hline SA (Max & Mean & 19.30 & 18.31 & 17.06 & 19.49 & 19.83 & 4.508 & 0.001 \\
\hline core 32 ) & SD & 4.84 & 4.30 & 3.86 & 5.43 & 5.49 & 4.500 & 0.001 \\
\hline FA (Max & Mean & 10.14 & 9.61 & 10.65 & 11.66 & 11.53 & & \\
\hline core 20) & SD & 2.75 & 1.86 & 2.84 & 3.21 & 3.14 & $5.66 \%$ & $<0.001$ \\
\hline FC (Max & Mean & 9.75 & 10.07 & 10.37 & 10.20 & 11.25 & & \\
\hline core 20 ) & SD & 3.05 & 2.69 & 2.89 & 2.64 & 2.78 & 2.557 & 0.039 \\
\hline AI (Max & Mean & 8.62 & 7.69 & 8.81 & 8.83 & 9.17 & 3130 & 0015 \\
\hline core 16 ) & SD & 2.16 & 2.02 & 2.64 & 2.77 & 2.80 & 3.130 & 0.015 \\
\hline Total (Max & & 47.83 & 45.67 & 46.90 & 50.17 & 51.78 & & \\
\hline core 88 ) & & 9.07 & 7.49 & 9.72 & 10.93 & 10.17 & 4.305 & 0.002 \\
\hline Table 4. Co & mpar & of of $O$ & $Q$ Dom & ains $\mathrm{BC}$ & sed on & Type of & Malocc & Iusion \\
\hline $\begin{array}{l}\mathrm{A}=\text { Social asp } \\
\text { mpact }\end{array}$ & ects; Ff & Facial a & hetics; & & & onent; A & & \\
\hline value $<0.05$ & s sign & ant & & & & & & \\
\hline
\end{tabular}

When we compared the mean total QOLQ score between different types of malocclusion, there were statistically significant differences observed [Table 4]. The post hoc comparison with the Bonferroni test showed that Class II malocclusion had statistically significantly higher OQLQ scores than Class I Open bite (mean difference $=6.11, \mathrm{P}=0.004$ ) and Class II Deep bite (mean difference $=4.88, \mathrm{P}=0.015$ ).

\section{DISCUSSION}

In the present study, the reliability of the questionnaire was 0.712 for the self-esteem scale. Acceptable alpha was between 0.7 and 0.9 as per Bowling's recommendation, so questionnaire reliability was accepted. 18

In this study, we have used the Index of Orthodontic treatment need (IOTN) 18. IOTN as a valid screening tool for orthodontic patients has been proven previously. Several studies have agreed that the IOTN - DHC accurately measures the severity of the malocclusion. ${ }^{19,20,21}$

A high correlation between malocclusion and self-esteem of female patients is confirmed by this study, which also proves that enhancing dental aesthetics improves one's selfesteem. These results are in agreement with those of other studies. ${ }^{10,22}$

Our study was done to find out the self-esteem of only female patients. When we compared the SE score between different types of malocclusion, it was found there was no statistical significance seen in total SE and PSE scores, but NSE scores showed significant differences. In our study, female patients with increased severity of malocclusions showed statistically significant lower self-esteem than those with mild malocclusions, which was in agreement with previous studies. ${ }^{11,21}$

In severe malocclusions, oral functions such as phonetics, mastication, and lip profile were also affected along with aesthetics and these will limit social interaction leading to higher negative self-esteem.

Patients who had Class II proclination and class II deep bite type of malocclusion had significantly higher negative SE compared to other types. Our results showed significant contrast to another study, which concluded that adolescent females noticed crowding of maxillary anterior teeth more negatively than lip protrusion or overjet. ${ }^{23}$

Our study confirms the findings of Sardenberg et al. ${ }^{24}$ confirmed the effect of overjet on negative self-esteem. In previous research on an adolescent population, anterior crowding was associated with more negative self-esteem than the protrusion.

Our results indicated both abnormal lip protrusion and deep bite leads to lower RSE and OQLQ in adult female orthodontic patients. These results are similar to a previous study of self-esteem involving female Asian University students. ${ }^{25}$ The aesthetic concerns of adult females seem to be markedly different from those of adolescent females.6,7,8

As this study has shown, the OQLQ is suitable for evaluating the psychological effects of malocclusion in adult female orthodontic patients. Future studies need to address differences in OQLQ of adult female patients with diverse cultural backgrounds and changes in the OQLQ after completion of orthodontic treatment. 


\section{CONCLUSIONS}

In this self-esteem study of treatment seeking adult female orthodontic patients, it was found that severe Class II associated deep bite and protrusive lip profile may have lower SE and QOL scores than those with crowding, open bite, and class III malocclusion. Evaluating the psychological effects of malocclusion in adult females, OQLQ proves to be a valid tool.

Data sharing statement provided by the authors is available with the full text of this article at jemds.com.

Financial or other competing interests: None.

Disclosure forms provided by the authors are available with the full text of this article at jemds.com.

\section{REFERENCES}

[1] Priya S. Evaluation of quality of life and self-esteem in patients with malocclusion. Dent Oral Craniofac Res 2015;1(3):63-5.

[2] Cofré E, Rodríguez K. Impact of dentofacial esthetics in self-esteem. A review of the literature. Int J Med Surg Sci 2018;5(1):22-7.

[3] De Couto Nascimento V, De Castro Ferreira Conti AC, De Almeida Cardoso M, et al. Impact of orthodontic treatment on self-esteem and quality of life of adult patients requiring oral rehabilitation. Angle Orthod 2016;86(5):839-45.

[4] Afroz S, Rathi S, Rajput G, et al. Dental esthetics and its impact on psycho-social well-being and dental self confidence: a campus based survey of north Indian university students. J Indian Prosthodont Soc 2013;13(4):455-60.

[5] Jung MH. An evaluation of self-esteem and quality of life in orthodontic patients: effects of crowding and protrusion. Angle Orthod 2015;85(5):812-9.

[6] Graber LW, Lucker GW. Dental esthetic self-evaluation and satisfaction. Am J Orthod 1980;77(2):163-73.

[7] Dimberg L, Arnrup K, Bondemark L. The impact of malocclusion on the quality of life among children and adolescents: a systematic review of quantitative studies. Eur J Orthod 2015;37(3):238-47.

[8] Anthony SN, Zimba K, Subramanian B. Impact of malocclusions on the oral health-related quality of life of early adolescents in Ndola, Zambia. Int J Dent 2018;2018:7920973.

[9] Heravi F, Farzanegan F, Tabatabaee M, et al. Do malocclusions affect the oral health-related quality of life? Oral Health Prev Dent 2011;9(3):229-33.
[10] Zhou Y, Wang Y, Wang X, et al. The impact of orthodontic treatment on the quality of life a systematic review. BMC Oral Health 2014;14:66.

[11] Badran SA. The effect of malocclusion and self-perceived aesthetics on the self-esteem of a sample of Jordanian adolescents. Eur J Orthod 2010;32(6):638-44.

[12] Gazit-Rappaport T, Haisraeli-Shalish M, Gazit E. Psychosocial reward of orthodontic treatment in adult patients. Eur J Orthod 2010;32(4):441-6.

[13] Phillips C, Beal KNE. Self-concept and the perception of facial appearance in children and adolescents seeking orthodontic treatment. Angle Orthod 2009;79(1):12-6.

[14] McKiernan EX, McKiernan F, Jones ML. Psychological profiles and motives of adults seeking orthodontic treatment. Int J Adult Orthodon Orthognath Surg 1992;7(3):187-98.

[15] Sinclair SJ, Blais MA, Gansler DA, et al. Psychometric properties of the rosenberg self-esteem scale: overall and across demographic groups living within the United States. Eval Health Prof 2010;33(1):56-80.

[16] Cunningham SJ, Garratt AM, Hunt NP. Development of a condition-specific quality of life measure for patients with dentofacial deformity: I. Reliability of the instrument. Community Dent Oral Epidemiol 2000;28(3):195-201.

[17] Rosenberg M. Society and the adolescent self-image. Revised edn. Middletown, CT: Wesleyan University Press Retrieved 1989:11.

[18] Bowling A. Research methods in health: investigating health and health services. $4^{\text {th }}$ edn. UK: McGraw-Hill Education 2014: p. 536.

[19] Dawoodbhoy I, Delgado-Angulo EK, Bernabé E. Impact of malocclusion on the quality of life of Saudi children. Angle Orthod 2013;83(6):1043-8.

[20] Hassan AH. Orthodontic treatment needs in the western region of Saudi Arabia: a research report. Head Face Med 2006;2(1):2.

[21] Bellot-Arcís C, Almerich-Silla JM. Psychosocial impact of malocclusion in Spanish adolescents. Korean J Orthod 2013;43(4):193-200.

[22] De Carvalho Sales Peres SH, Goya S, Cortellazzi KL, et al. Self-perception and malocclusion and their relation to oral appearance and function. Cien Saude Colet 2011;16(10):4059-66.

[23] Shaw BA, Liang J, Krause N. Age and race differences in the trajectories of self-esteem. Psychol Aging 2010;25(1):8494.

[24] Sardenberg F, Martins MT, Bendo CB, et al. Malocclusion and oral health-related quality of life in Brazilian school children: a population-based study. Angle Orthod 2013;83(1):83-9.

[25] Jung MH, Heo W, Baek SH. Effects of malocclusion on the self-esteem of female university students. Korean J Orthod 2008;38(6):388-96. 